\title{
In vitro Tissue Culture Technique as Tool for micro propagation of Lepidium sativum L. Plant under Abiotic Stress Conditions
}

\author{
Khadiga Gaafar Abdelaleem ${ }^{1}$, Inas Mohammed Abd El-Wahab Khamis ${ }^{1,2}$, \\ Ohud Mohammed Saed Aldawsari ${ }^{1}$ and Monira Saad Ali Alsubaie ${ }^{1}$
}

\author{
${ }^{1}$ Department of Biology, University College in Alkhafji, Hafr Elbatin University, Saudi Arabia \\ ${ }^{2}$ Medicinal and Aromatic Plant Departments, Desert Research Center, Ministry of Agriculture and Land Reclamation, Egypt. \\ Corresponding author email: khadigaalaim@hotmail.com
}

\begin{abstract}
This study was carried out at biology Lab, Biology Department, University College in ALKhafji, University of HAFR ALBATIN, to study the effect of MS salts strength, and sucrose concentration on micro propagation and phytochemical composition of Lepidium sativum Plant, using MS medium at five salt strength (1.0,1.5,2.0,2.5 and $3.0 \mathrm{mg} \backslash \mathrm{L}) \mathrm{MS}$ salt strength and sucrose at five concentration $(30.0 \mathrm{~g}, 45.0 \mathrm{~g}, 60.0 \mathrm{~g}, 75.0$ $g$ and $90.0 \mathrm{~g}) \backslash$ L. Ethanolic extracts and DPPH reagent were used to test the antioxidant activity.

Lepidium sativum Plant used in folk medicine in Sudai Arabia, known as Garden cress belongs to Brassicaceae family. It is very famous in folk medicine. The tissue culture technique is a rapid method to propagate plants in vitro, especially medicinal plants for producing medicinal component. Through in vitro culture we can control the environmental conditions of plants; it enables us to study the effect of some factors like sucrose concentration and salt strength that determine growth of plants and chemical constituent. Impact of these stresses the plant micro propagation and the content of plants from active substances which plays a role as antioxidant was varied. For micro propagation, the effect of MS salt strength showed that, the use of MS media salt at double MS salt concentration (2.0 MS salt) obtained highest leaf

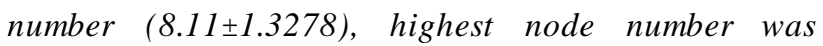
(1.933 \pm 0.62098$)$ and highest shoot length $(4.608 \pm 0.5828 \mathrm{~cm})$ both were induced by basal MS (1.0 MS salt), while highest root length $(3.787 \pm 0.3958)$ obtained at triple MS salt strength (3.0 MS salt (. Effect of sucrose concentration, MS media supplemented by $30 \mathrm{~g}$ sucrose obtained highest leaf number, highest shoot and root length $(5.655 \pm 1.1076 ; 4.608 \pm 0.5828$ and $2.985 \pm 0.3952)$ respectively. For antioxidant activity data represented that antioxidant activity increase with increasing salt strength and sucrose concentration. Our results suggested that increasing sucrose concentration
\end{abstract}

decrease leafnumber, shoot and root length, on the other hand increase antioxidant activity. While increasing MS salt strength decrease node number and shoots length, while root length and antioxidant activity was increase. The results contained in this research are the first study to Effect of some environmental stress on in vitro propagation and antioxidant activity of Lepidium sativum at Saudia Arabia..

Keywords-Antioxidant Activity, Phenolic contents, In vitro, Lepidium sativum, Micro propagation, MS media, Stress.

\section{INTRODUCTION}

Medicinal plants have been used from ancient time for their medicinal values. Nowadays, the crude extracts samples from medicinal plants have been shown interest for the development and preparation of alternative traditional medicine [1]. Plants are the best sources for chemical ingredients or phytochemical agents for cure of different diseases. Medicinal plants are an inexhaustible source of molecules with very different biological and pharmacological activities. Lepidium sativum is an edible plant. Seeds, leaves and roots of these plants have economic importance. It is widely used in folk medicine, known as garden cress, it is annual herb belonging to the Brassicaceae family, and it is widely cultivated in temperate climates throughout the world for different medicinal uses [2]. The plant is called "Hab el Rashaad" or "Thufa" in Saudi Arabia and is a popular herbal plant grown in many regions of Saudi Arabia, such as Hijaz, AL-Qaseem, and the Eastern Province [3 \& 4]. Plant stress is a controversial environmental impediment affecting the plant growth and leading to an extensive loss in agricultural productivity. The environmental stress on plants can be biotic or abiotic. Biotic stress includes the wastage caused by various living organisms. Abiotic stress involves various environment factors including 
aridity, salinity, heavy metal, high and low temperature stress that affect the plant growth and development, leading to decrease crop yield. Lepidium sativum Plant being grown in arid and semiarid regions is severely affected by both biotic stresses and abiotic stresses. Different agronomic practices, traditional breeding methods and biotechnological method were used for the management of different stresses and development of stress tolerance in several crops. However, all these methods were found to be unfavorable and less effective. Recently, tissue culture technique has proved to be more appropriate and cost- effective technique for the development of stress tolerance in plants. The technique carrying out under controlled environmental conditions with minimal time and space has very high potential for the development of various stress-tolerant crop plants. Therefore, in vitro selection technique provides new vista for improving stress tolerance in Lepidium sativum Plant for environmental sustainability.

Drought stress caused by water deficit, is probably the most impacting adverse condition and the most widely encountered by plants, not only in crop fields but also in wild environments. According to published statistics, the percentage of drought affected land area in the world in 2000 was double that of 1970 [5].

Another major environmental factor that limits crop productivity, mainly in arid and semiarid regions is high salinity. Approximately $19.5 \%$ of the irrigated soils in the world have elevated concentrations of salts either in the soil or in the irrigation water [6], damaging both the economy and the environment $\left[\begin{array}{l}7 \& \\ \&\end{array}\right]$. The deleterious effects of salinity on plant growth are as sociated with low osmotic potential of soil solution (water stress), nutritional imbalance, specific ion effect (salt stress), or a combination of these factors [9]. Abiotic stress leads to a series of morphological, physiological, biochemical, and molecular changes that adversely affect plant growth and productivity [10]. The resulting of these stresses induces production of reactive oxygen species, and accruement of hormones [11]. Secondary metabolites play a major role in the adaptation of plants to the environment and in overcoming stress conditions [12].

The similarities of the effects induced by the stress in the plant cultured in vitro and in vivo conditions suggest that the in vitro system can be used as an alternative to field evaluations for studying the general effect of water-stress on plant growth and development. The tissue culture technique is a rapid method to propagate plants in vitro, especially, medicinal plants. The present study is carried out at biology Lab, Biology Department, University College in ALKhafji, University of HAFR ALBATIN, to study the effect of MS salts strength, sucrose concentration on micro propagation and anti-oxidant activity of Lepidium sativum plant, Using MS medium at
$(1.0,1.5, \quad 2.0,2.5$ and 3.0) $\mathrm{mg} \backslash \mathrm{L}$ salt strength and $(30.0,45.0,60.0,75.0$ and 90.0$) \backslash \mathrm{g} \backslash \mathrm{L}$ sucrose concentrations.

\section{MATERIAL \& METHOD}

\subsection{Plant Tissue Culture}

\subsubsection{Plant materials:}

Lepidium sativum seeds were purchased from local market of khafji city, Saudi Arabia.

\subsubsection{Surface sterilization of Explant:}

Lepidium sativum seeds were surface sterilized for $30 \mathrm{sec}$ with $70 \%$ ethanol followed by washing with sterilized distilled water, followed by sterilization by $5 \%$ chlorex supplemented by few drop of liquid soap for ten minute and washed thoroughly with autoclaved distilled water five times The sterilized seeds were dried with sterilized filter paper [13].

\subsubsection{Establishment of Aseptic Seedlings}

Media preparation: Murashige and Skoog [14] medium was used in the present study, sucrose (3\%), and $\mathrm{pH}$ of the medium was adjusted to 5.8 , then solidifying with $0.7 \%$ agar. The media was autoclaved at $121{ }^{\circ} \mathrm{C}$ and 15 lbs. pressure for $15 \mathrm{~min}$

\subsubsection{Inoculation of explants:}

The seed inoculation was done with help of sterile forceps. After inoculation glass culture bottles were wrapped and incubate in growth room. Culture development and maintenance: Explants were maintained at temperature $25 \pm 2^{0} \mathrm{C}$, with 8 hours light and 16 hours dark condition Photoperiods, light intensity at 1000 to 2000 Lux. Data were reported after four week.

\subsubsection{Effect of salt strength on Culture Medium} on the plant micro propagation

Lepidium sativum sterilized seeds were inoculated on the MS basal medium with different salt strength (1.0, 1.5, 2.0, 2.5 and 3.0) salt strength per $\mathrm{mg} \backslash \mathrm{L}$

2.1.6. Effect of Sucrose concentration on Culture Medium on the plant micro propagation

Lepidium sativum sterilized seeds were inoculated on the MS basal medium with different sucrose concentration, (30.0, 45.0, 60.0, 75.0 and 90.0) $\mathrm{g} \backslash \mathrm{L}$.

\subsection{Phytochemical Analysis}

Explants were washed with distilled water to remove the trace of medium, used for extract preparation.

\subsubsection{Extracts:}

Whole plant Samples from each treatment were soaked separately with ethyl alcohol $70 \%$ in conical flasks for $24 \mathrm{~h}$ at $40^{\circ} \mathrm{C}$ on water bath. After 24 hours it was filtered with Whatman No.1 filter paper. The filtrates were evaporated with rotary evaporator apparatus to obtained extraction for each sample. The extracts were 
stored in sample bottles at $4^{\circ} \mathrm{C}$ prior to use for further analyses.

\subsubsection{Determination of Total Phenolic Content (TPC):}

The total phenolic content for all plant samples was determined by using Folin- Ciocalteu method [15].

2.2.3. Antioxidant Scavenging Activity (DPPH) Assay:

The effect of methanolic extracts on DPPH (2,2diphenyl-1-picrylhydrazyl) radicals was estimated according to [16].

\subsection{Statistical analysis of the data}

All experiments were replicated ten times having 10 explants per culture bottle and the experiment was repeated twice. Statistical analysis was carried using a statistical software program. Data were reported as means \pm standard error

\section{RESULTS AND DISCUSSIONS}

Table (1) indicated that the different MS salt strength used effect on Lepidium sativum plant micro propagation, the effect of MS salt strength showed that, the use of MS media salt at double MS salt concentration (2.0 MS salt) obtained highest leaf number (8.11 \pm 1.3278$)$, highest node number was $(1.933 \pm 0.62098)$ and highest shoot length $(4.608 \pm 0.5828 \mathrm{~cm})$ both were induced by basal MS $(1.0$ MS salt), while highest root length $(3.787 \pm 0.3958)$ obtained at triple MS salt strength (3.0 MS salt). MS supplemented by different sucrose concentration effect on Lepidium sativum plant micro propagation, MS media supplemented by $30 \mathrm{~g}$ sucrose obtained highest leaf number, highest shoot and root length $(5.655 \pm 1.1076$; $4.608 \pm 0.5828$ and $2.985 \pm 0.3952$ ) respectively, this result supported by [17] who reported sucrose at $30 \mathrm{~g} / \mathrm{l}$ and $45 \mathrm{~g} / 1$ concentration gave significantly higher mean number of Shoots and root of banana plant, while highest node number (1.949) was

Induced by $75 \mathrm{~g} \backslash \mathrm{L}$ sucrose.

Polyphenol synthesis and accumulation in plants is generally stimulated in response of abiotic or biotic strsess [18].

Methanol extracts of studied samples were examined for their total phenolic content and antioxidant activities using a DPPH assay and expressed as $\mathrm{IC}_{50}$ value.
Table.1: Effect of MS Medium Salt Strength and Sucrose Concentration on Micro Propagation of Lepidium sativum plant after four weeks of culture.

\begin{tabular}{|c|c|c|c|c|c|}
\hline \multicolumn{6}{|c|}{ Salt strength on Culture Medium (mgll) } \\
\hline 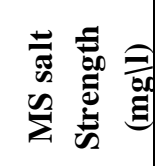 & $\begin{array}{l}\bar{F} \\
\tilde{W} \\
\tilde{D}^{2} \\
\tilde{L}\end{array}$ & $\frac{n}{n}$ & $\tilde{N}_{\Sigma}^{\infty}$ & $\begin{array}{l}n \\
\tilde{n} \\
\Sigma\end{array}$ & $\tilde{n}_{\Sigma}^{\infty}$ \\
\hline TPC \% & 12.42 & 12.44 & 12.84 & 13.08 & 13.74 \\
\hline $\begin{array}{l}\mathrm{IC}_{50} \\
\mu \mathrm{gm} / \mathrm{ml}\end{array}$ & 181.33 & 212.27 & 245.51 & 257.46 & 276.12 \\
\hline \multicolumn{6}{|c|}{ Sucrose concentration on Culture Medium (g】l) } \\
\hline 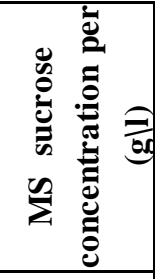 & $\begin{array}{l}\bar{\pi} \\
\tilde{E} \\
\tilde{D}^{2} \\
\tilde{N} \\
\sum\end{array}$ & $\stackrel{\infty}{\stackrel{\infty}{\sim}}$ & $\stackrel{\infty}{0}^{\infty}$ & $\stackrel{+\infty}{\sim}$ & $\stackrel{60}{\circ}$ \\
\hline TPC \% & 12.42 & 12.56 & 12.85 & 12.97 & 13.23 \\
\hline $\begin{array}{l}\mathrm{IC}_{50} \\
\mu \mathrm{gm} / \mathrm{ml}\end{array}$ & 181.33 & 203.94 & 232.11 & 249.90 & 253.16 \\
\hline
\end{tabular}

Data in Table (2) showed that, total phenolic compounded (TPC) was increase with salt and sugar concentration increasing, which highest values were in MS 3.0 salt strength and $90 \mathrm{~g} \backslash 1$ sucrose and the lowest one was in MS as basal. The highest total phenolic content values (13.74) and (13.23), also antiradical assets as IC50 highest values (276.12) $\mu \mathrm{gm} / \mathrm{ml}$ and (253.16) $\mu \mathrm{gm} / \mathrm{ml}$ were determined for the plants culture on MS media contained 3.0 MS salt strength (mgll) strength and sucrose at concentration 90 g\l (S3) respectively. Higher anti-oxidant activity of the extracts of the samples parallels to a high content of phenol in them, these result in agreement with [19]. Salinity causes hyperosmotic and hypertonic stress in plants, for the protection against oxidative stress, caused by salinity, antioxidants are produced. Some researchers have also reported a high positive correlation between free radical-scavenging activity and the total concentration of phenolic compounds in plant extracts [20]. The polyphenolic compounds include flavonoids and tannins and other active materials are reported to scavenge free radicals, superoxide and hydroxyl radical by single electron [21]. 
Table.2: Effect of MS medium salt strength and Sucrose concentration on The Total Phenolic Content and

Antioxidant Activities of Lepidium sativum plant grown in vitro.

\begin{tabular}{|c|c|c|c|c|c|}
\hline 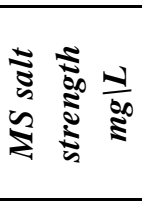 & 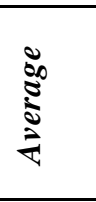 & s & 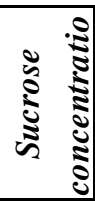 & 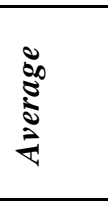 & t⿹ \\
\hline \multicolumn{6}{|c|}{ Leave } \\
\hline MS & 5.655 & 1.107653 & S 30 & 5.655 & 1.107653 \\
\hline $1.5 \mathrm{MS}$ & 6.991 & 0.530828 & $\mathrm{~S} 45$ & 3.423 & 0.242606 \\
\hline $2 \mathrm{MS}$ & 8.11 & 1.327791 & S60 & 3.4085 & 0.19038 \\
\hline $2.5 \mathrm{MS}$ & 3.623 & 0.407423 & S75 & 4.223 & 0.564856 \\
\hline 3MS & 4.101 & 0.125516 & S90 & 2.245 & 0.103099 \\
\hline \multicolumn{6}{|c|}{ Node } \\
\hline MS & 1.933 & 0.620989 & S 30 & 1.933 & 0.620989 \\
\hline $1.5 \mathrm{MS}$ & 1.141 & 0.102268 & S45 & 1.67 & 0.126588 \\
\hline $2 \mathrm{MS}$ & 1.672 & 0.34587 & S60 & 1.3152 & 0.133498 \\
\hline $2.5 \mathrm{MS}$ & 1.768 & 0.345057 & S75 & 1.949 & 0.238702 \\
\hline 3MS & 1.025 & 0.016816 & S90 & 1.017 & 0.017 \\
\hline \multicolumn{6}{|c|}{ Stem } \\
\hline MS & 4.608 & 0.582826 & S 30 & 4.608 & 0.582826 \\
\hline $1.5 \mathrm{MS}$ & 4.383 & 0.441852 & $\mathrm{~S} 45$ & 3.761 & 0.263166 \\
\hline $2 \mathrm{MS}$ & 3.893 & 0.408085 & S60 & 2.457 & 0.303813 \\
\hline $2.5 \mathrm{MS}$ & 2.216 & 0.303107 & S75 & 3.536 & 0.596462 \\
\hline 3MS & 3.65 & 0.109067 & S90 & 0.674 & 0.073684 \\
\hline \multicolumn{6}{|c|}{ Root } \\
\hline 1.0 MS & 2.985 & 0.395239 & S 30 & 2.985 & 0.395239 \\
\hline $1.5 \mathrm{MS}$ & 2.547 & 0.206393 & S45 & 1.977 & 0.149064 \\
\hline $2.0 \mathrm{MS}$ & 2.172 & 0.283176 & S60 & 1.7815 & 0.167886 \\
\hline $2.5 \mathrm{MS}$ & 0.979 & 0.05986 & S75 & 2.253 & 0.200793 \\
\hline 3.0 MS & 3.787 & 0.395865 & S90 & 0.9 & 0.238607 \\
\hline
\end{tabular}

$I_{50}=$ Median Inhibition Concentration (concentration that reduces the effect by 50\%)

\section{CONCLUSION}

Increase salt strength and sucrose concentration resulted in osmotic stress and induces the production of antioxidant metabolites. The results showed that MS salt strength played a significant role of micro propagation, phenols accumulation and antioxidant activity of Lepidium sativum plant the current study show that the strength of MS salts and sucrose concentration can be used to induce antioxidant metabolites of Lepidium sativum plant. The data contribute for furthermore extensive studies of the biologically active compounds of in vitro cultures of this valuable plant depending on the nourishing elements

\section{REFERENCES}

[1] Chatoui, K.; A. Talbaoui, A.; Aneb, M., Bakri, Y.; Harhar, H. and Tabyaoui, M. (2008). Phytochemical Screening, Antioxidant and Antibacterial activity of Lepidium sativum seeds from Morocco. J. Mater. Environ. Sci. 7(8) 2938-2946.

[2] Gokavi, S. S.; Malleshi, N. G. and Guo, M. (2004). Plant. Food. Hum. Nutr. 59, 105-111.

[3] Shail, S.; Manjari, D.; Neeroj, K. and Gupta, L.N. (2016). Nutritional importance of Lepidium sativum. Int. J. of Pharmacy and Analytical Research. 5 (1): 152-160.

[4] Rahman, M. A.; JMossa, S.; Al-Said, M. S. and AlYahya, M. A. (2004). Medicinal plant diversity in the flora of Saudi Arabia 1: a report on seven plant families, Fitoterapia. vol. 75, no. 2, pp. 149-161, 2004.

[5] Isendahl N. and Schmidt G. (2006). Drought in the Mediterranean-WWF policy proposals; A. WWF Report, Madrid.

[6] Jin T.C., Chang Q., Li W.F., Yin D.X., Li Z.J., Wang D.L., Liu B., Liu L.X. (2010). Stress inducible expression of GmDREB1 conferred salt tolerance in transgenic alfalfa. Plant Cell Tissue and Organ Culture; 100 219-227.

[7] Rengasamy P. (2010). Soil processes affecting crop production in salt-affected soils. Functional Plant Biology; 37 255-263.

[8] Yang Y.L., Shi R.X., Wei X.L., Fan Q., An L.Z. (2010). Effect of salinity on antioxidant enzymes in calli of the halophyte Nitraria tangutorum Bobr. Plant Cell Tissue and Organ Culture; 102 387-395.

[9] Gomez-Cadenas A., Arbona V., Jacas J., PrimoMillo E., Talon M. (2003). Abscisic acid reduces leaf abscission and increases salt tolerance in citrus plants. Journal of Plant Growth Regulation; 21 234240.

[10] Wang W.X., Vinocur B., Shoseyov O., Altman A. (2001). Biotechnology of plant osmotic stress tolerance: physiological and molecular considerations. Acta Horticulturae; 560 285-292.

[11] Cheong Y.H., Chang H.S., Gupta R., Wang X., Zhu T., Luan S. (2002). Transcriptional profiling reveals novel interactions between wounding, pathogen, abiotic stress, and hormonal responses in Arabidopsis. Plant Physiology 2002; 129: 661-677.

[12] Ahamed, R.; Mujeeb, M.; Anwar, F. and Ahmad, A. (2015). Phytochemical analysis and evaluation of anti-oxidant activity of methanolic extract of Lepidium sativum L. seeds. Der. Pharm. Lett., 7 (7), pp. 427-434.

[13] Khadiga G. AbdElaleem, Rasheid S. Modawi and Mutasim M. Khalafalla. (2015)" Micro tuber Induction of two Potato (Solanumtuberosum L.) 
Varieties namely, Almera and Diamant".

International Research Journal of Biological

Sciences, Vol. 4(3), 1-6.

[14] Murashige, T; Skoog, F. (1962). "A Revised Medium for Rapid Growth and Bio Assays with Tobacco Tissue Cultures". Physiologia Plantarum. 15 (3): 473-497.

[15] Odabasoglu, F.; Aslan, A.; Cakir, A.; Suleyman, H.; Karago, Y. and Halici, M. (2004). Comparison of antioxidant activity and phenolic content of three lichen species. Phytotherapy Research, 18 (11): 938941.

[16] Gardeli, C.; Papageorgiou, V.; Mallouchos, A.; Kibouris, T.; Komaitis, M. (2008). Essential oil composition of Pistacia lentiscus L. and Myrtus communis L. Evaluation of antioxidant capacity of methanolic extracts. Food Chem. 107: 1120-1130.

[17] Ekhlas, A. Morfeine. (2014). Effect of Sucrose and Glucose Concentrations on Micropropagation of Musa sp.cv. Grand Naine. Journal of Applied and Industrial Sciences, 2 (2): 58-62, ISSN: 2328-4595 (PRINT), ISSN: 2328-4609 (ONLINE)

[18] Cheynier, V., Comte, G., Davies, K. M., Lattanzio, Vand Martens, S. (2013). Plant phenolics: Recent advances on their biosynthesis, genetics, and ecophysiology. Plant Physiology and Biochemistry, 72, 1-20.

[19] Ely Zayova, Maria Petrova, Milena Nikolova and Lyudmila Dimitrova. (2016). Effect of Medium Salt Strength on the Micropropagation, Phenolic Content and Antioxidant Activity of Arnica montana L., Threatened Plant Species. Bio Bulletin 2(1): 6-13.

[20] Wangensteem W., Vinocur B., Altman A. (2004). Plant responses to drought, salinity and extreme temperatures: towards genetic engineering for stress tolerance. Planta; 218 1-14.

[21] Chatoui, K.; Talbaoui, A.; Aneb, M.; Bakri, B.; Harhar, H. and Tabyaoui, M. (2016). Phytochemical screening, antioxidant and antibacterial activity of Lepidium sativum seeds from Morocco. J. Mater. Environ. Sci., 7 (8), pp. 2938-2946. 